\title{
Effects of Grain Size and Grain Boundary Stability on Mechanical and Fatigue Properties of Nanocrystalline Nickel Thin Films
}

\author{
Yoshikazu Nakai ${ }^{1, * 1}$, Ryota Takeshige ${ }^{1, * 2}$, Tsuyoshi Hirai ${ }^{1, * 2}$ and Shoichi Kikuchi ${ }^{2}$ \\ ${ }^{1}$ Department of Mechanical Engineering, Kobe University, Kobe 657-8501, Japan \\ ${ }^{2}$ Department of Mechanical Engineering, Shizuoka University, Hamamatsu 432-8561, Japan
}

\begin{abstract}
The effects of grain size and grain boundary stability on the mechanical and fatigue properties of nanocrystalline nickel thin films were examined. We found that the grain size of nanocrystalline nickel thin films tended to decrease with the amount of sodium allylsulfonate, and the grain size on the solution side was larger than that on the substrate side. The dependence of the grain size on the $0.2 \%$ proof strength, the tensile strength, and the fatigue limit could be expressed by the Hall-Petch equation. The $0.2 \%$ proof strength and tensile strength of the annealed film are lower than those of the as-deposited film, while the fatigue limit of the annealed film was higher than that of the as-deposited film. The grain boundary stability and dislocation density are responsible for the effect of annealing. The fracture strain of the annealed film is lower than that of the as-deposited film, indicating that annealing makes the film brittle. [doi:10.2320/matertrans.Z-M2021837]
\end{abstract}

(Received February 1, 2021; Accepted June 17, 2021; Published August 2, 2021)

Keywords: grain size effect, grain boundary stability, fatigue limit, mechanical properties, nanocrystalline nickel thin film

\section{Introduction}

Nanocrystallization is one of the most promising techniques to improve the tensile and fatigue strengths of metallic materials, ${ }^{1-5)}$ and their thin films are now being widely used for micro-electro-mechanical systems. The electrodeposition method will be the easiest method to obtain a uniform nanocrystalline structure in thin films, ${ }^{6}$ ) and the effect of the grain size on the mechanical and the fatigue properties has thus been studied ${ }^{7-9}$ ) for as-deposited films. The grain boundaries of nanocrystalline metal in the asdeposited state often have a non-equilibrium structure including excess volume. ${ }^{10,11)} \mathrm{Hu}$ et al. indicated that the grain boundary stability provides an alternative dimension in addition to the grain size for producing novel nanograined metals with extraordinary properties. ${ }^{10}$ ) The nonequilibrium grain boundary structure, such as one with excess volume, can be changed to the equilibrium one by annealing at low temperatures without affecting the grain size. ${ }^{11-14)}$ This grain boundary relaxation during annealing leads to high angle grain boundaries. ${ }^{11)}$ At the same time, the annealing results in grain boundary diffusion, which causes grain boundary relaxation and grain boundary segregation of solutes and impurities. Since local structural analysis using a threedimensional atom probe is required for separating the grain boundary relaxation from the segregation, ${ }^{11)} \mathrm{Hu}$ et al. ${ }^{10)}$ was comprehensively expressed as grain boundary stability without separating them for qualitative discussions.

The grain boundary relaxation during annealing brought about the hardening effect. ${ }^{15,16)}$ It is different from the grain boundary stability in materials made by the equal-channeling angular pressing (ECAP) method ${ }^{17,18)}$ or severe plastic deformation by high pressure torsion, ${ }^{19)}$ which is concerned with the disordered networks and junction dislocations inducing long-range stress field.

Since most of the previous studies on the electrodeposited nickel film ${ }^{9,20-24)}$ were focused on the effect of nanocrystal-

\footnotetext{
${ }^{* 1}$ Corresponding author, E-mail: nakai@mech.kobe-u.ac.jp

${ }^{* 2}$ Graduate Student, Kobe University
}

line, the fatigue tests have been conducted on the specimen thicker than $100 \mu \mathrm{m}$ although the fatigue damage in submicron-thick copper film is not similar to that in bulk material as reported by Kondo et al. ${ }^{25)}$ Tanaka et al. reported the effect of the grain size on the fatigue properties of the nanocrystalline thin film with the thickness of $10 \mu \mathrm{m} ;{ }^{9)}$ however, the thickness effect on fatigue strength is still unknown. The effect of the grain boundary stability also has not yet been studied. Meanwhile, Goto et al. studied the grain boundary stability for materials made by the ECAP method. $^{26)}$

Despite the major concern on the fatigue strength of nanocrystalline materials has been the grain size effect, the evaluation of grain size of nanocrystalline materials has not been well established. The grain size of nanocrystalline material is usually analyzed by the Scherrer method ${ }^{27)}$ using $\mathrm{X}$-ray diffraction (XRD) or transmission electron microscopy (TEM). However, it has been recognized that the grain size evaluated by these methods does not always give actual value, and electron backscatter diffraction (EBSD) is now considered to be the best method for analyzing the grain size of material. ${ }^{28)}$

In the present study, the EBSD method for measuring the grain size of a nanocrystalline electrodeposited film is established, and the effects of the grain size and grain boundary stability on the mechanical and fatigue properties are investigated.

\section{Material and Experimental Procedures}

\subsection{Material}

Nickel thin films were produced by electrodeposition using sulfamate solution. ${ }^{9)}$ The composition of the solution in $\mathrm{g} / \mathrm{L}$ was as follows: $250 \mathrm{Ni}\left(\mathrm{SO}_{3} \mathrm{NH}_{2}\right)_{2}$ (nickel sulfamate), 30 $\mathrm{H}_{3} \mathrm{BO}_{3}$ (boric acid), $10 \mathrm{NiCl}_{2}$ (nickel chloride), and 0.4 $\mathrm{CH}_{3}\left(\mathrm{CH}_{2}\right)_{10} \mathrm{CH}_{2} \mathrm{OH}$ (sodium lauryl sulphate). $\mathrm{C}_{3} \mathrm{H}_{5} \mathrm{NaO}_{3} \mathrm{~S}$ (sodium allylsulfonate) at the amount of $0,0.4,0.8$, or 1.6 $\mathrm{g} / \mathrm{L}$ was added to the solution to control the microstructure of the electrodeposited film. A polished stainless-steel plate and a pure nickel plate were employed for the substrate (cathode) 


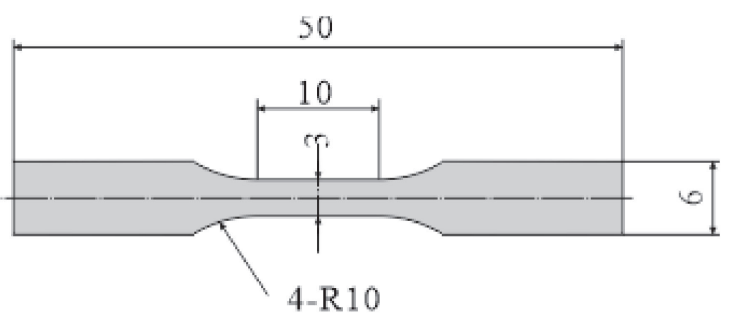

(a) Tension test specimen

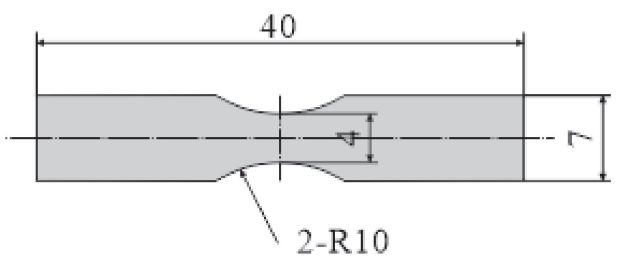

(b) Fatigue test specimen

Fig. 1 Shape and dimensions of specimens (in $\mathrm{mm}$ ).

and the anode, respectively. The temperature of the hot-water circulation bath was kept constant at $40^{\circ} \mathrm{C}$. The $\mathrm{pH}$ of the solution was maintained at 4.0 by adding $\mathrm{H}_{2} \mathrm{NO}_{3} \mathrm{~S}$ (sulfamate acid). The solution was stirred with a magnetic stirrer to avoid pit formation. The current density was kept constant at $0.25 \mathrm{~mA} / \mathrm{mm}^{2}$ by using a constant current supply. The deposition time was $30 \mathrm{~min}$ to obtain a specimen with a thickness of $10 \mu \mathrm{m}$, and it took $180 \mathrm{~min}$ to obtain a sample with a thickness of $60 \mu \mathrm{m}$. This sample was employed to examine the microstructure during the electrodeposition. To change the grain boundary stability, annealing at $250^{\circ} \mathrm{C}$ for $1 \mathrm{~h}$ was conducted in ambient air.

After the deposition, the thin films were removed from the substrate and subjected to characterization, mechanical, and fatigue tests as free-standing films. The shape and dimensions of the specimens are shown in Fig. 1 for the (a) tensile and (b) fatigue tests.

The crystal structures of the specimens were analyzed by $\mathrm{X}$-ray diffraction (XRD) with $\mathrm{Cu} \mathrm{K} \alpha$ radiation and EBSD. Residual stress was measured by the $\cos \alpha$ method using the XRD pattern obtained on the surface of the film. The binding energy of the surface layer was analyzed by X-ray photoelectron spectroscopy (XPS) with $\mathrm{Mg} \mathrm{K} \alpha$ radiation to investigate the elements contained in the film.

\subsection{Testing}

Tensile tests were carried out using a stepping-motordriven machine with a capacity of $50 \mathrm{~N}$ under a cross-head speed of $0.01 \mathrm{~mm} / \mathrm{s}$. Since the measurement of the elongation in the reduced parallel section is difficult for thin specimens, it was estimated from the grip-to-grip displacement by the procedure shown below. Since the plastic deformation in other parts of the reduced parallel section (Part A) is much smaller than that in the Part A, the plastic elongation of Part A can be approximated from the measured grip-to-grip elongation subtracting the elastic displacement by equations in Appendix, where Young's modulus was evaluated from the linear part of the force and grip-to-grip elongation relationship, and the grip-to-grip distance was employed for $l_{1}+2\left(l_{2}+l_{3}\right)$ instead of the actual specimen length.

Fatigue tests were performed using an electrodynamic testing machine with a capacity of $490 \mathrm{~N}$ in air under a sinusoidal loading wave with a stress ratio $R=\sigma_{\min } / \sigma_{\max }$ of 0.1 and a frequency of $20 \mathrm{~Hz}$.

\section{Experimental Results}

\subsection{Characterization of microstructure \\ 3.1.1 Grain size}

Figure 2 shows the inverse pole figure (IPF) maps of the substrate side of the electrodeposited film with a thickness of $10 \mu \mathrm{m}$; they were obtained by EBSD analysis with the step size of $50 \mathrm{~nm}$, observed from the direction perpendicular to the surface, where the grain boundary was defined as the misorientation of $15^{\circ}$ or more. The annealed films were employed for the analysis because the Kikuchi pattern did not appear for the as-deposited film except for the films made without sodium allylsulfonate $(0.0 \mathrm{~g} / \mathrm{L})$. For the film made without sodium allylsulfonate, the grain size did not change by the annealing. The grain size for the film made with sodium allylsulfonate also is considered not have changed by the annealing as reported by Jan and Atzmon ${ }^{12)}$ and Matsui et al. ${ }^{11)}$ The grain size decreases with increasing amount of added sodium allylsulfonate.

Figure 3 shows the difference in the microstructure of films between the substrate and the solution sides. For the film made without sodium allylsulfonate, the grain size on the

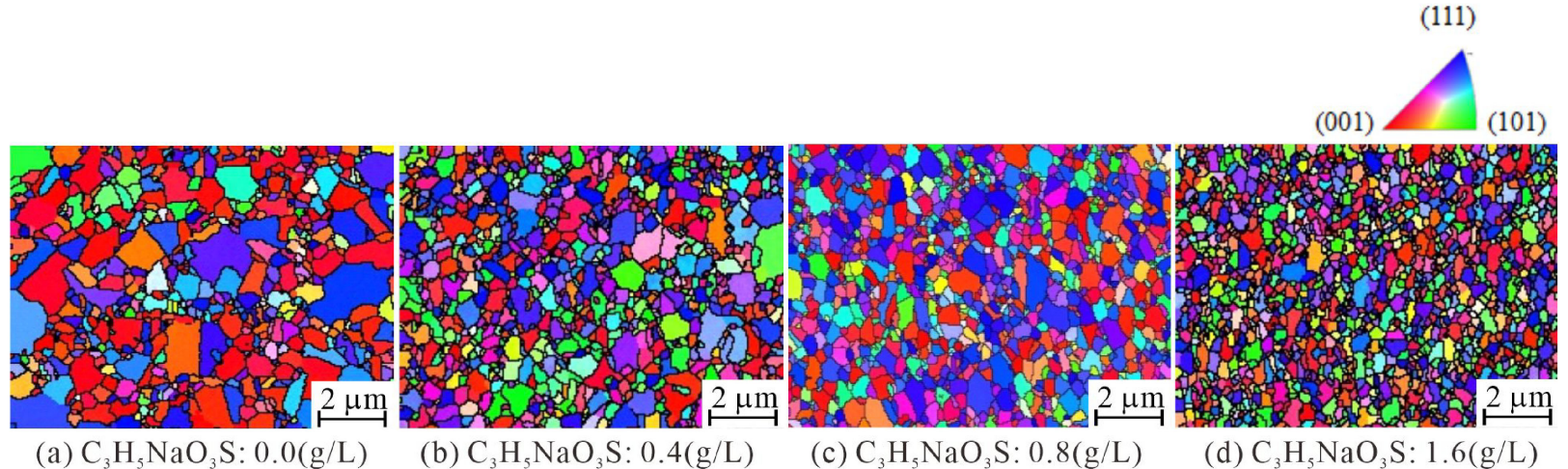

Fig. 2 Inverse pole figure (IPF) maps of substrate side of as-deposited film with a thickness of $10 \mu \mathrm{m}$. 


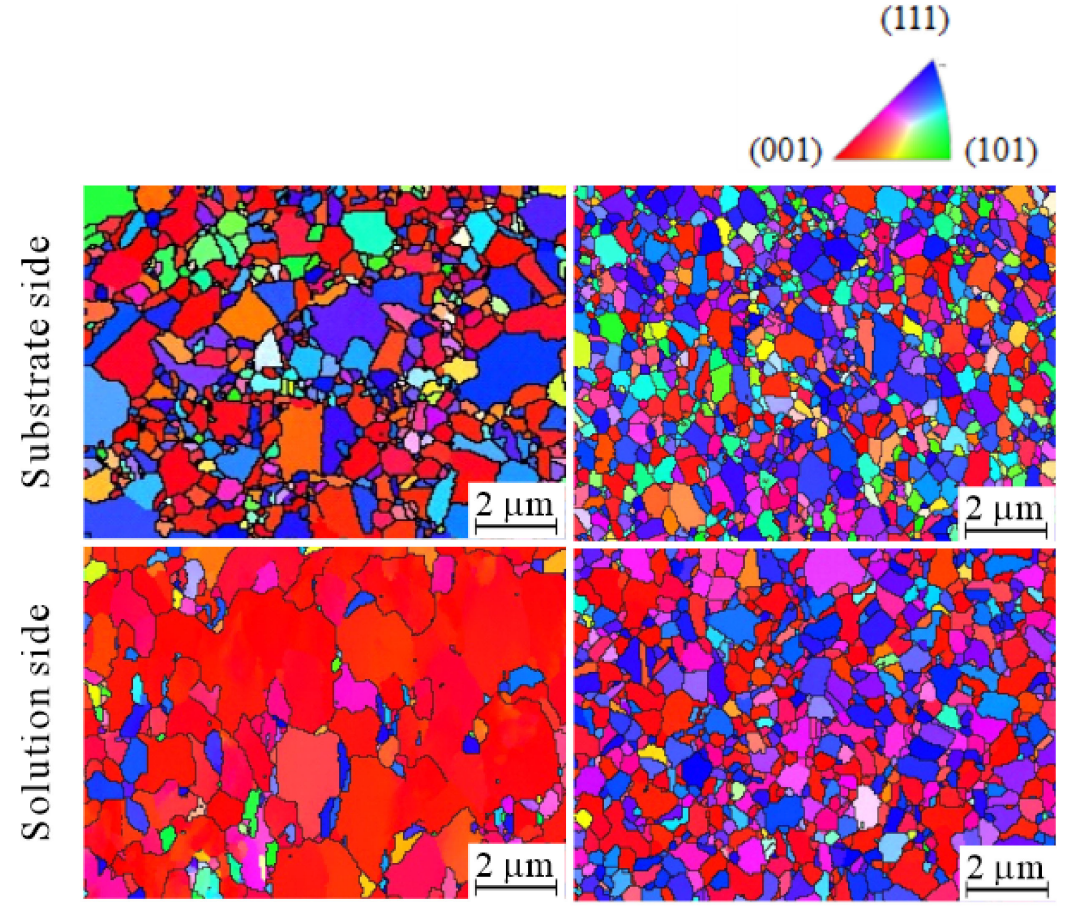

(a) $\mathrm{C}_{3} \mathrm{H}_{5} \mathrm{NaO}_{3} \mathrm{~S}: 0.0$ (g/L) (b) $\mathrm{C}_{3} \mathrm{H}_{5} \mathrm{NaO}_{3} \mathrm{~S}: 0.8$ (g/L)

Fig. 3 Comparison of microstructure of the film between substrate side and solution side.

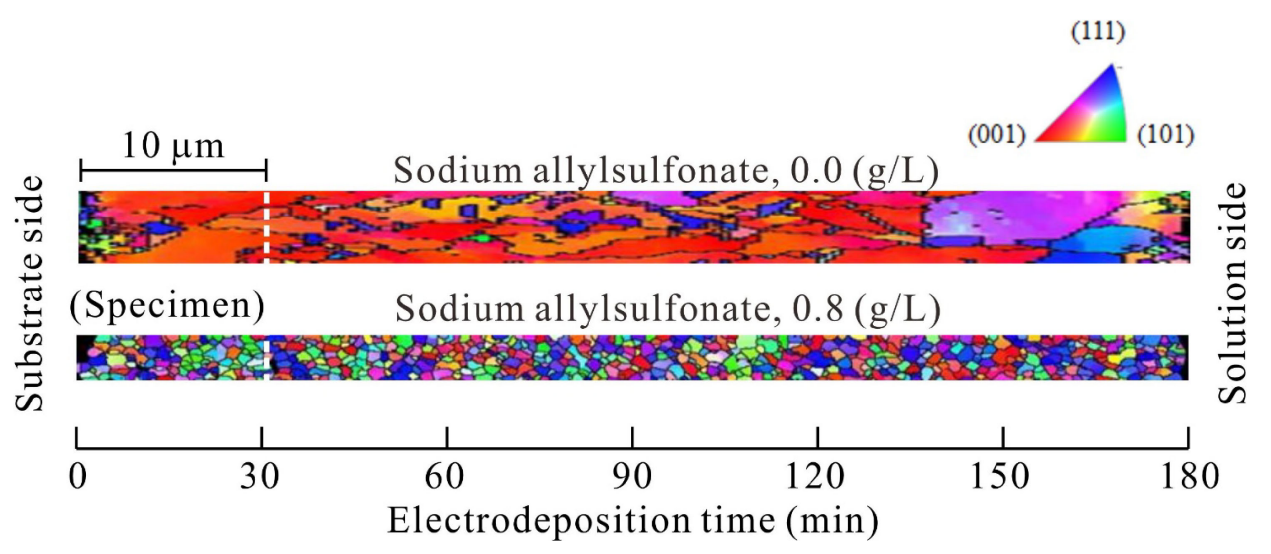

Fig. 4 IPF maps of the crosssection of the films with thickness of $60 \mu \mathrm{m}$.

substrate side is very different from that on the solution side; the orientation is almost random on the substrate side, whereas grains have preferred orientation of the (001) direction on the solution side. Because of the preferred orientation, it is very difficult to distinguish each grain. For the film made with $0.8 \mathrm{~g} / \mathrm{L}$ sodium allylsulfonate, the orientation is almost random and the grain size is almost the same on both sides. Films with the thickness of $60 \mu \mathrm{m}$ were fabricated to examine the changes in orientation and grain size during electrodeposition. IPF maps of the films are shown in Fig. 4. In the film made without sodium allylsulfonate $(0.0 \mathrm{~g} / \mathrm{L})$, the preferred-orientation structure, similar to the solution side, is dominant, whereas the orientation of grains is random just below the surface on the substrate side. For the film made with $0.8 \mathrm{~g} / \mathrm{L}$ sodium allylsulfonate, the grain size is similar to that at the surface shown in Fig. 3(b), but it is not clear for the film made without sodium allylsulfonate because the grain boundaries are not clear owing to the preferred-orientation structure.

Since the effect of the step size in the EBSD analysis should be clarified to achieve the precise measurement of the grain size, the effect of the step size on the measured grain size was examined. As shown in Fig. 5, the measured grain size decreased with decreasing step size, and it approached a constant value when the step size was less than one-tenth of the measured grain size. This constant value is considered to be the actual grain size. Although the grain size differs between the substrate and solution sides, the value on the solution side will be employed because the strength of each specimen is controlled by large grains in accordance with the weakest link theory.

3.1.2 X-ray diffraction and photoelectron spectroscopy

Figure 6 shows the intensity of the diffracted X-ray on the solution side. The full width at half maximum (FWHM), $\beta$, 


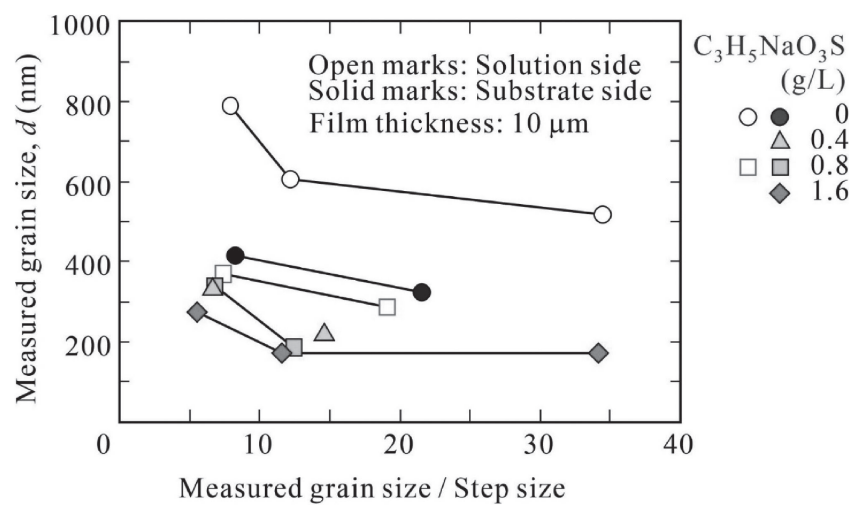

Fig. 5 Step size dependence of measured grain size in EBSD analysis.

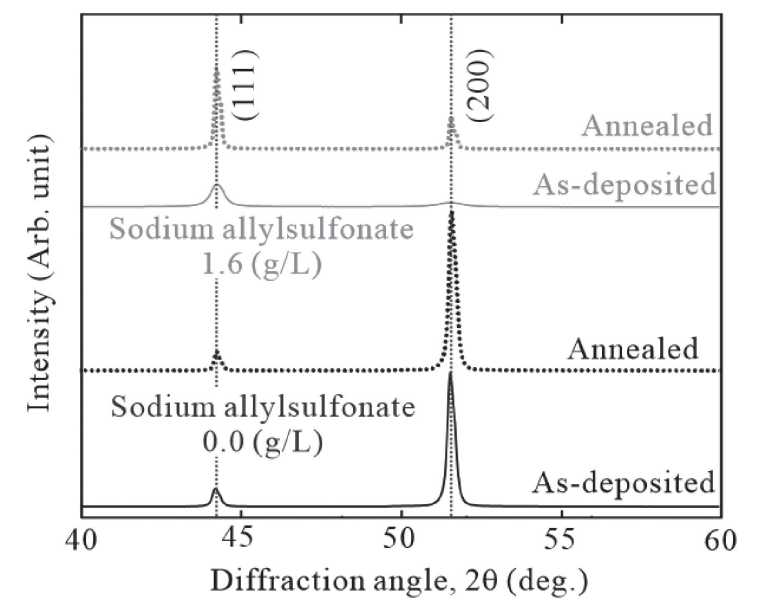

Fig. 6 Intensity of diffracted X-ray on the solution side.

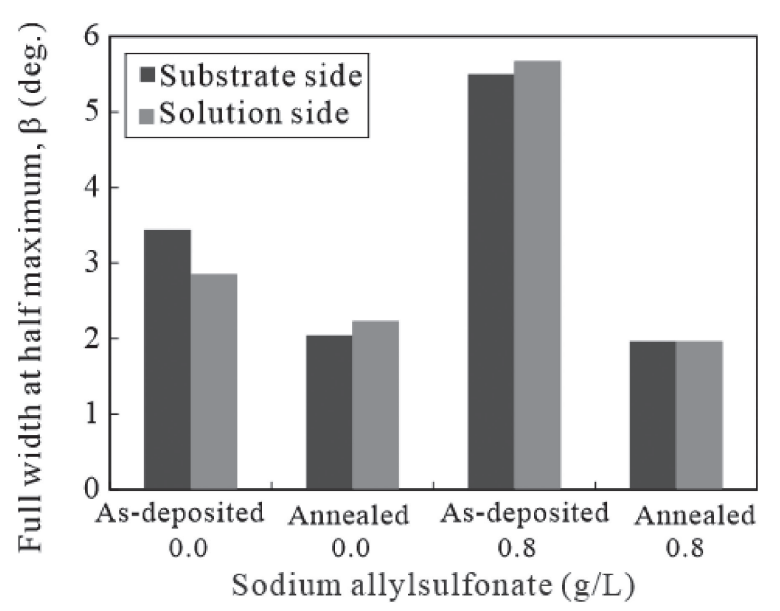

Fig. 7 Full width of half maximum (FWHM) measured by X-ray diffraction (XRD).

decreases and the peak intensity increases upon annealing. As shown in Fig. 7, $\beta$ on the solution side is almost the same as that on the substrate side, except for the as-deposited film made with $0.8 \mathrm{~g} / \mathrm{L}$ sodium allylsulfonate. The FWHM affects the capability of EBSD analysis, i.e., the EBSD analysis can be performed for films with $\beta$ values smaller than $3^{\circ}$, whereas it was impossible for films with $\beta$ values larger than $3^{\circ}$. Since the FWHM is related to the dislocation density, the capability of the EBSD analysis depends on the dislocation density, i.e., films without annealing have high dislocation density.

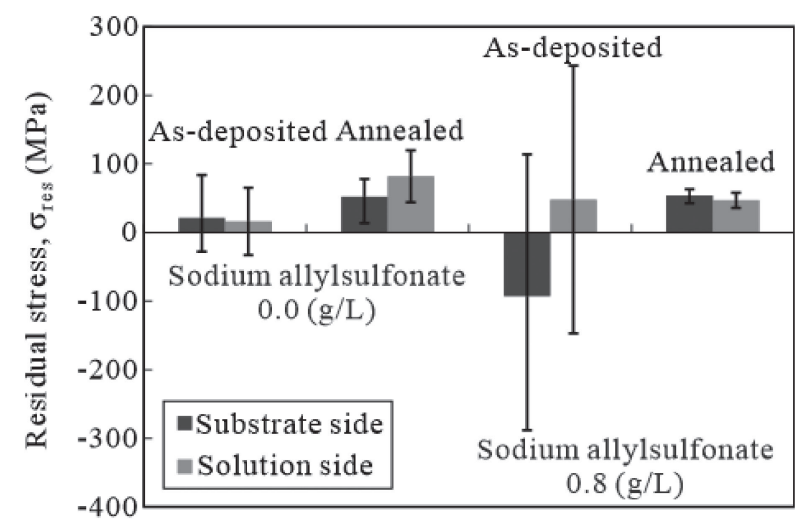

Fig. 8 Residual stress measured by $\cos \alpha$ method using X-ray diffraction (XRD).

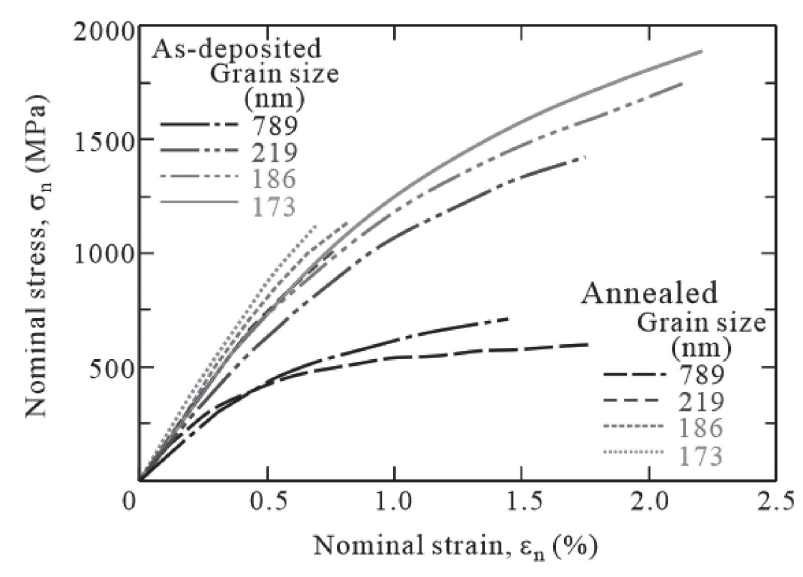

Fig. 9 Stress-strain relationships.

The residual stress measured by the $\cos \alpha$ method using the XRD profile is shown in Fig. 8, where the error bars indicate the standard deviation at each measurement site. No significant differences in residual stress are observed between the sites.

X-ray photoelectron spectroscopy (XPS) was conducted on the solution side to detect $\mathrm{S}, \mathrm{Na}, \mathrm{Ni}$, and $\mathrm{O}$ elements. Since the spectral peaks of $\mathrm{S}$ and $\mathrm{Na}$ were not detected, sodium allylsulfonate $\left(\mathrm{C}_{3} \mathrm{H}_{5} \mathrm{NaO}_{3} \mathrm{~S}\right)$ is considered to not be contained in the film. Although the spectral peaks of $\mathrm{Ni}$ and $\mathrm{O}$ were detected, those of $\mathrm{NiO}$ and $\mathrm{Ni}_{2} \mathrm{O}_{3}$ were not indicating that oxides were not formed.

\subsection{Tensile test}

Figure 9 shows the stress-strain relationships, where the strain was calculated from the estimated elongation of the reduced parallel section as described in 2.2. For as-deposited film, the tensile strength $\sigma_{\mathrm{UTS}}$ is higher and fracture strain $\varepsilon_{\mathrm{f}}$ is larger for smaller grain size film, however, the difference of those values for films made with sodium allylsulfonate are small. The stress-strain relationships of the annealed films up to fracture are almost identical to those of the as-deposited films; however, the fracture strain $\varepsilon_{\mathrm{f}}$ of the annealed films is much smaller than those of the as-deposited films, except for films with the grain size of $789 \mathrm{~nm}$ (electrodeposited without sodium allylsulfonate). This difference is explained not by the residual stress, but it is considered to be an effect of the grain boundary structure that causes the difference in grain 


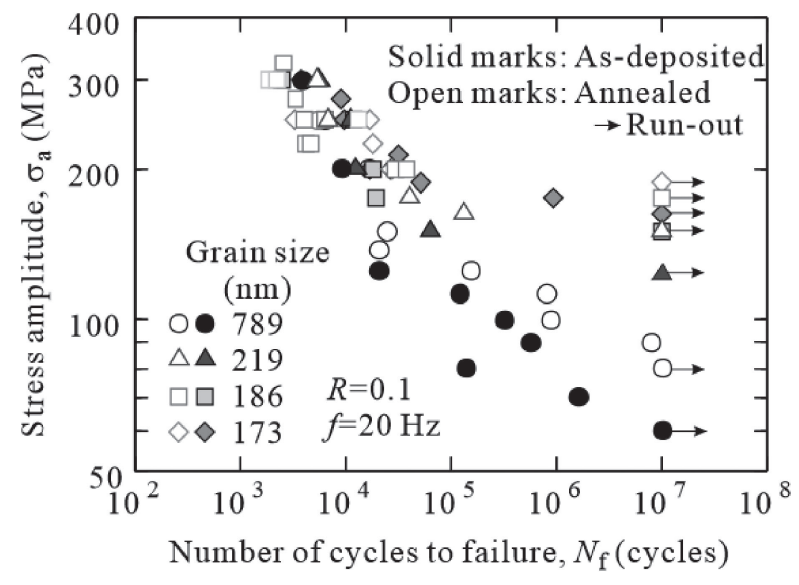

Fig. 10 S-N curves.

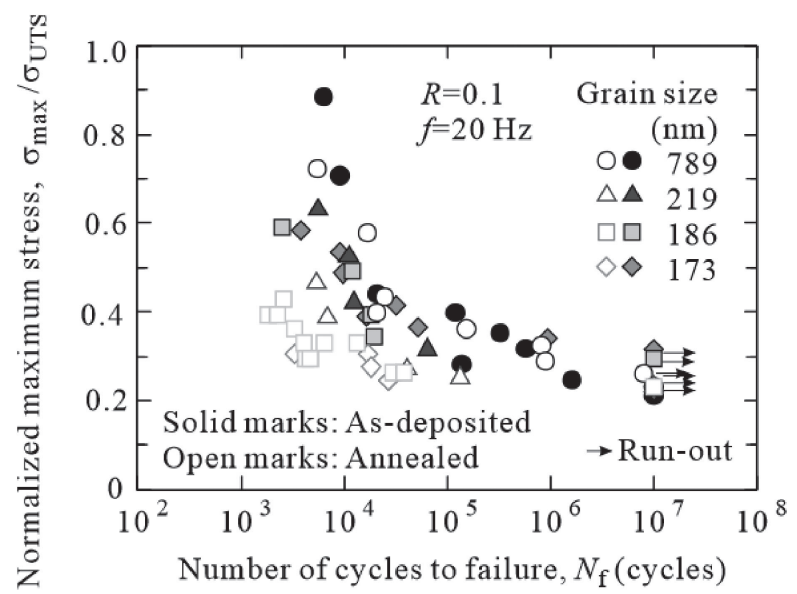

Fig. 11 Normalized S-N curves.

boundary stability, ${ }^{15,16)}$ including change of excess volume and/or grain boundary relaxation during annealing. The existence of sodium allylsulfonate, which was contained less than the detection limit of XPS, may affect this difference.

\subsection{Fatigue test}

$\mathrm{S}-\mathrm{N}$ curves of films are shown in Fig. 10, where $\sigma_{\mathrm{a}}$ is the stress amplitude in each loading cycle and $N_{\mathrm{f}}$ is the number of cycles to failure. A clear fatigue limit exists for all films, and the effects of grain size and annealing are marked in the long-life region near the fatigue limit, although the effects are negligible in the short-life region, indicating that the effects of those factors are different between fatigue crack initiation life and propagation life. For long life region, the fatigue crack initiation life must be dominant, and the fatigue crack propagation life must be dominant for short life region.

The maximum stress at each loading cycle, $\sigma_{\max }=$ $\sigma_{\mathrm{a}} /(1-R)$, normalized by the tensile strength $\sigma_{\mathrm{UTS}}$ is plotted against $N_{\mathrm{f}}$ in Fig. 11. The effects of grain size and annealing are small in the long-life region near the fatigue limit as reported for conventional materials. ${ }^{29,30)}$ The effects are large in the short-life region, but $\sigma_{\max } / \sigma_{\mathrm{UTS}}=1$ at $N_{\mathrm{f}}=1 / 2$ for every material. Generally, the effects of grain size and annealing on $\sigma_{\max }$ vs. $N_{\mathrm{f}}$ relationship are much smaller than those on $\sigma_{\mathrm{a}}$ vs. $N_{\mathrm{f}}$ relationship, then this relationship can be used for rough estimation of fatigue strength from tensile strength.

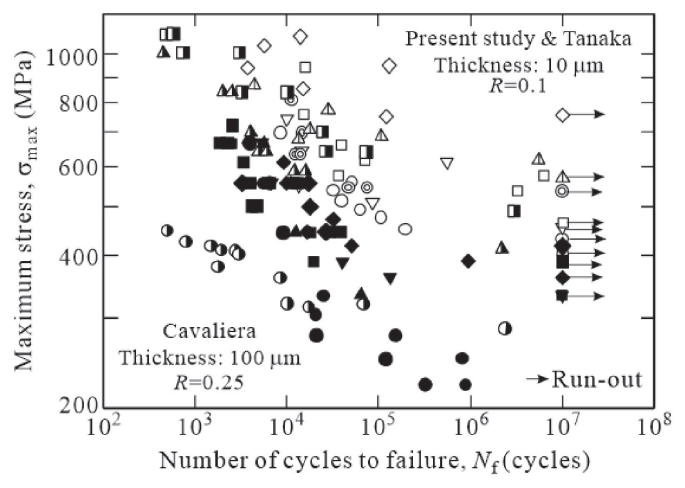

Grain size Present study - $789(\mathrm{~nm})$ $\nabla 219(\mathrm{~nm})$ - $186(\mathrm{~nm})$ $173(\mathrm{~nm})$ Tanaka $67.7(\mathrm{~nm})$ $\nabla 35.2(\mathrm{~nm})$ $\square 16.4(\mathrm{~nm})$ $\diamond 14.1(\mathrm{~nm})$ $\odot 10.3(\mathrm{~nm})$ $\triangle 9.0(\mathrm{~nm})$ Cavaliere A $270(\mathrm{~nm})$ - $40(\mathrm{~nm})$

Fig. 12 Comparison of S-N curves for $R=0.1$ obtained by Tanaka et al. ${ }^{9)}$ and Cavaliera. ${ }^{23)}$

Figure 12 shows the $S-N$ curves of the present films together with those reported by Cavaliera ${ }^{23}$ ) and Tanaka et al., ${ }^{9)}$ where the data obtained by the present study and by Tanaka et al. were conducted using films with the thickness of $10 \mu \mathrm{m}$ and fatigue test was conducted under the stress ratio, $R$, of 0.1 , while the thickness was $100 \mu \mathrm{m}$ and $R=0.25$ for Cavaliere's data. From the EBSD analysis shown in Fig. 4, it can be inferred that the crystallographic structure of the film with the thickness of $100 \mu \mathrm{m}$ is similar to that of $10 \mu \mathrm{m}$.

Generally, the fatigue strength, which is the maximum stress at a given fatigue life, $N_{\mathrm{f}}$, the effect of grain size is pronounced at high cycle fatigue regime near fatigue limit whereas it is small in the low cycle fatigue regime. Cavaliera reported that the fatigue strength for film with grain size, $d$, of 20 is higher than that with $d=270 \mathrm{~nm}$, and he reported that not only the grain size, ductility also affects the fatigue strength. According to Cavaliera, this is the reason why the fatigue strength of the film with $d=40 \mathrm{~nm}$ is much smaller than that of comparable grain size film, $d=20 \mathrm{~nm}$ without explaining why the ductility of these materials is so different. Except the Cavaliera's data for $d=40 \mathrm{~nm}$, the fatigue strength of films with thickness of $100 \mu \mathrm{m}$ show comparable to that of $10 \mathrm{~nm}$ at similar grain size, indicating that fatigue strength is lower for thinner film under the same stress ratio because the fatigue strength is usually smaller for higher stress ratio.

Figure 13 shows the relationship between the maximum stress at the fatigue limit, $\sigma_{\text {max,w }}$, and the tensile strength $\sigma_{\mathrm{UTS}}$. The fatigue limit is almost proportional to the tensile strength, where the proportionality of the annealed film is larger than that of the as-deposited film, while the proportionality of the annealed film is close to that reported by Tanaka et al. ${ }^{9)}$

\section{Discussion}

\subsection{Effect of grain size}

The mechanical properties obtained in the present study are given in Table 1. For most of the conventional alloys and metals, the Hall-Petch relationship is well known to describe the effect of grain size effect on the yield strength $\sigma_{\mathrm{Y}}$ or the proof strength $\sigma_{0.2}$, and this relationship was theoretically derived for the fatigue limit using the blocked slip band model. ${ }^{31-33)}$ Figure 14 shows the Hall-Petch relationships for the tensile strength $\sigma_{\mathrm{UTS}}, 0.2 \%$ proof strength $\sigma_{0.2}$, and fatigue 


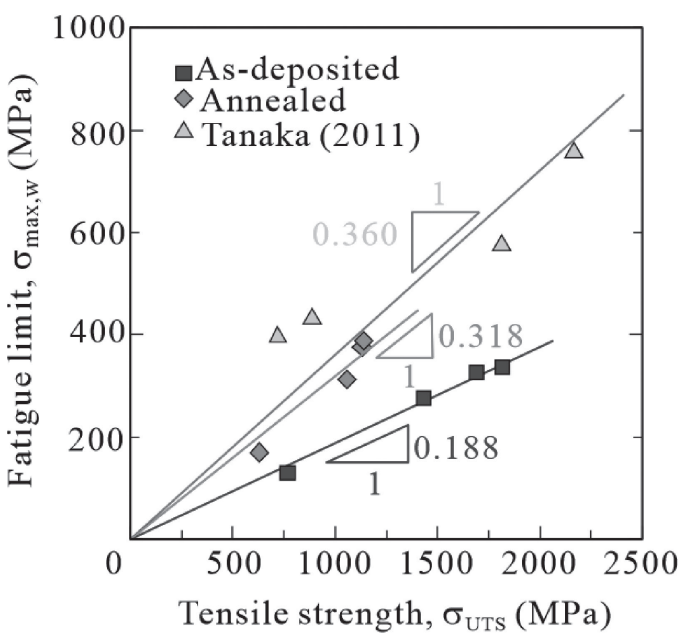

Fig. 13 Relation between fatigue limit and tensile strength.

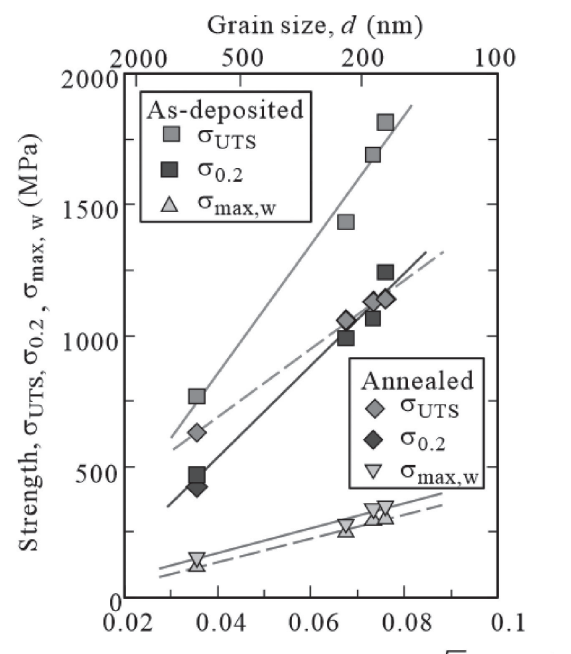

Inverse square root of grain size, $1 / \sqrt{d}\left(\mathrm{~nm}^{-1 / 2}\right)$

Fig. 14 Hall-Petch plots.

limit $\sigma_{\text {max,w }}$ of the present materials, where $\sigma_{0.2}$ was not obtained, except for the material with the largest grain size because the fracture strain $\varepsilon_{\mathrm{f}}$ was lower than $0.2 \%$. For every strength, the effect of grain size can be expressed by the Hall-Petch relationship, i.e., strength increases linearly with the inverse square root of grain size, $1 / \sqrt{d}$. Annealing decreases $\sigma_{\mathrm{UTS}}$, although it increases $\sigma_{\mathrm{max}, \mathrm{w}}$. The grain
Grain size, $d(\mathrm{~nm})$

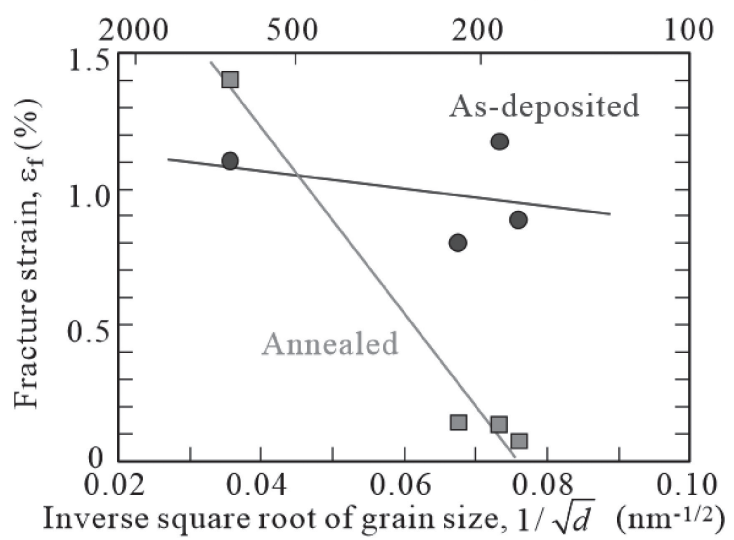

Fig. 15 Fracture strain in tension test.

boundary stability must affect the former, and the dislocation density, the latter.

As shown in Fig. 15, in the tension test, the fracture strain $\varepsilon_{\mathrm{f}}$ of the annealed film is lower than that of the as-deposited film, suggesting that the deformation through grain boundary is suppressed by annealing, and the effect of the grain size on the fracture strain $\varepsilon_{\mathrm{f}}$ for the annealed film is larger than that for the as-deposited film, indicating that the effect of annealing (grain boundary stability) is marked for smallgrained films. Since the critical volume of thin film is much smaller than that of bulk material, the scatter of fracture strain of thin films seems to be much larger than that of bulk materials.

\subsection{Problem in grain size evaluation}

Figure 16 shows the Hall-Petch plot of the proof strength $\sigma_{0.2}$ for pure nickels, where the results obtained by Thompson et al. are for bulk materials, ${ }^{34)}$ and others are for electrodeposited thin film. ${ }^{7,8,35)}$ The relationship for the present films is very different from other results. On the material side, the grain boundary stability of the present films is not similar to other results; however, its effect is negligible compared with the effect of grain size. Another difference is the grain size evaluation method. Other than in the present study, the grain size was evaluated by the Scherrer method or TEM. For grain size measurement, Sone recommended EBSD and scanning ion microscopy (SIM), since the Scherrer and TEM methods have some difficulties. ${ }^{35)}$ However, in most nanocrystalline

Table 1 Grain size and mechanical properties.

\begin{tabular}{|c|c|c|c|c|c|c|c|c|c|}
\hline \multirow[b]{2}{*}{$\begin{array}{c}\mathrm{C}_{3} \mathrm{H}_{5} \mathrm{NaO}_{3} \mathrm{~S} \\
(\mathrm{~g} / \mathrm{L})\end{array}$} & \multirow[b]{2}{*}{$\begin{array}{c}\text { Grain size } \\
d(\mathrm{~nm})\end{array}$} & \multicolumn{4}{|c|}{ As-deposited } & \multicolumn{4}{|c|}{ Annealed } \\
\hline & & $\begin{array}{c}0.2 \% \\
\text { proof } \\
\text { strength } \\
\sigma_{0.2}(\mathrm{MPa}) \\
\end{array}$ & $\begin{array}{c}\text { Tensile } \\
\text { strength } \\
\sigma_{\mathrm{UTS}} \\
(\mathrm{MPa}) \\
\end{array}$ & $\begin{array}{c}\text { Fracture } \\
\text { strain } \\
\varepsilon_{\mathrm{f}}(\%)\end{array}$ & $\begin{array}{c}\text { Fatigue limit } \\
\sigma_{\mathrm{w}}(\mathrm{MPa})\end{array}$ & $\begin{array}{c}0.2 \% \text { proof } \\
\text { strength } \\
\sigma_{0.2}(\mathrm{MPa})\end{array}$ & $\begin{array}{c}\text { Tensile } \\
\text { strength } \\
\sigma_{\text {UTS }}(\mathrm{MPa})\end{array}$ & $\begin{array}{c}\text { Fracture } \\
\text { strain } \\
\varepsilon_{\mathrm{f}}(\%)\end{array}$ & $\begin{array}{c}\text { Fatigue limit } \\
\sigma_{\mathrm{w}}(\mathrm{MPa})\end{array}$ \\
\hline 0.0 & 789 & 469 & 768 & 1.10 & 65 & 422 & 628 & 1.40 & 85 \\
\hline 0.4 & 219 & 990 & 1433 & 0.80 & 138 & - & 1058 & 0.14 & 156 \\
\hline 0.8 & 186 & 1065 & 1690 & 1.18 & 163 & - & 1130 & 0.13 & 188 \\
\hline 1.6 & 173 & 1241 & 1815 & 0.89 & 168 & - & 1141 & 0.07 & 194 \\
\hline
\end{tabular}




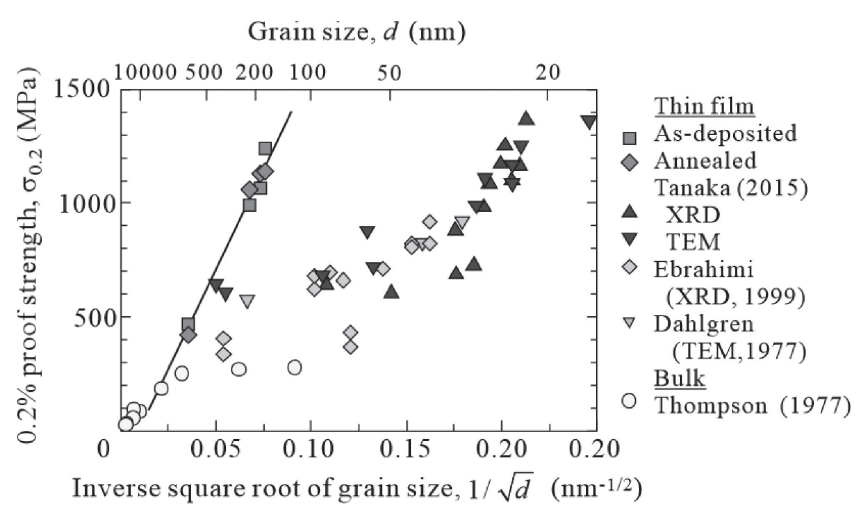

Fig. 16 Hall-Petch plots for $0.2 \%$ proof strength.

Table 2 Comparison between measured grain sizes. ${ }^{28)}$

\begin{tabular}{lccc}
\hline$d_{\mathrm{XRD}}(\mathrm{nm})$ & 22 & 16 & 14 \\
$d_{\mathrm{SIM}}(\mathrm{nm})$ & 2550 & 400 & 350 \\
\hline$d_{\mathrm{XRD}} / d_{\mathrm{SIM}}$ & 0.0086 & 0.040 & 0.040 \\
\hline
\end{tabular}

materials, the grain size has been evaluated by the Scherrer method, using FWHM in the XRD profile, as

$$
d=\frac{\lambda}{\beta \cos \theta}
$$

where $\lambda$ is the wavelength of the incident X-ray beam, $\beta$ is the FWHM, and $\theta$ is the Bragg angle. As described previously, $\beta$ increases with dislocation density, which usually exists in electrodeposited films; therefore, eq. (2) gives smaller values for films with high density of dislocations. The spread of the X-ray beam also should be considered.

The limit of the application of the Scherrer method was discussed by Miranda et al., ${ }^{36)}$ and they concluded that this method is valid when the grain size is smaller than $200 \mathrm{~nm}$. Table 2 shows the grain sizes evaluated by the Scherrer method using XRD, $d_{\mathrm{XRD}}$, and those using SIM methods, $d_{\mathrm{SIM}}{ }^{28)}$ The grain size evaluated by XRD is smaller than 0.040 times that evaluated by SIM, indicating that the value of $d_{\mathrm{XRD}}=14 \mathrm{~nm}$ is not valid although this is smaller than $200 \mathrm{~nm}$. As described before, the dislocation density of asdeposited film is very high, the size evaluated by Scherrer method must be dislocation cell size or subgrain size. This means that all data, except the present results, shown in Fig. 16 may have been obtained with incorrect grain sizes. The grain size of the present film evaluated using eq. (2) and $\beta$ indicated in Fig. 7 is less than $10 \mathrm{~nm}$, which is much smaller than that evaluated by EBSD when the effects of the dislocation density and the spread of the X-ray beam were not considered. Regarding the TEM observation, Sone reported that the texture and grain sizes were sometimes confused. $^{35)}$

\subsection{Effect of small defects}

It is well known that the effect of crack length on the fatigue limit is not simply derived from the threshold value of the stress intensity factor for cracks smaller than the intrinsic crack length, ${ }^{30,31,37-39)} a_{0}$, given by
Table 3 Intrinsic crack length.

\begin{tabular}{ccccc}
\hline $\begin{array}{c}\text { Grin size } \\
d(\mu \mathrm{m})\end{array}$ & $\begin{array}{c}\text { Fatigue limit } \\
\sigma_{\mathrm{w}}(\mathrm{MPa})\end{array}$ & $\begin{array}{c}\Delta K_{\mathrm{th}} \\
\left(\mathrm{MPam}^{1 / 2}\right)\end{array}$ & $\begin{array}{c}\text { Intrinsic crack } \\
\text { length } a_{0}(\mu \mathrm{m})\end{array}$ & $a_{0} / d$ \\
\hline 0.789 & 65 & 2.768 & 144 & 183 \\
0.186 & 163 & 1.635 & 8.00 & 43.0 \\
\hline
\end{tabular}

$$
a_{0}=\frac{1}{\pi}\left(\frac{\Delta K_{\mathrm{th}}}{\Delta \sigma_{\mathrm{w}}}\right)^{2}
$$

where $\Delta K_{\text {th }}$ is the threshold stress intensity factor of long crack and $\Delta \sigma_{\mathrm{w}}$ is the fatigue limit of smooth specimen without crack. More precisely, the fatigue limit of component with crack of length, $a$, is

$$
\frac{\Delta \sigma_{\mathrm{th}}}{\Delta \sigma_{\mathrm{w}}}=\sqrt{\frac{a_{0}}{a+a_{0}}}
$$

Therefore, $\Delta \sigma_{\text {th }} / \Delta \sigma_{\mathrm{w}}=1 / \sqrt{2}$ at $a=a_{0}$. Then, defects much smaller than $a_{0}$ is not deteriorated effect on the fatigue strength. The value of $a_{0}$ of the present films are shown in Table 3. Tanaka et al. ${ }^{31,32)}$ reported for low-carbon steels that $a_{0}$ is proportional to grain size $d$, for example, $a_{0}=17 d$ for $R=-1$ and $4.8 d$ for $R=0.4$, and Tanaka et al. reported for electrodeposited nickel film that $a_{0}=8.14 \mu \mathrm{m}$ for ultrafine grained film and $2.61 \mu \mathrm{m}$ for nanocrystalline film. ${ }^{40)}$ The values of the as-deposited film, shown in Table $3,{ }^{41)}$ are much larger than those reported values resulting from low fatigue limit; however, it indicates that defects, such as pit, did not affect the fatigue strength of the present film.

In this study, we employed the direct current (D.C.) method in which sodium allylsulfonate was added to obtain nanocrystalline thin film. On the other hand, nanocrystalline thin film free from texture can be obtained by the pulsedeposition by choosing optimum conditions, in which many parameters to be determined such as pulse on time, pulse off time, peak current density. ${ }^{42}$ ) The residual stress in films obtained by pulse plating is also smaller than that obtained by the D.C. method. Then, the next task is to study the effect of grain size and grain boundary stability on the mechanical and fatigue properties of nickel thin film fabricated by pulse plating.

\section{Conclusions}

In the present study, the effects of grain size and grain boundary stability on the mechanical and fatigue properties of nanocrystalline nickel thin films were examined, and the results obtained were as follows.

(1) The grain size of nanocrystalline material could be measured by the EBSD method when its step size was smaller than one-tenth of the actual grain size, whereas the XRD method cannot yield grain sizes of as-deposited film.

(2) The grain size of electrodeposited nickel thin films tended to increase with the amount of sodium allylsulfonate, and the grain size on the solution side was larger than that on the substrate side.

(3) The dependence of the $0.2 \%$ proof strength, the tensile strength, and the fatigue limit on the grain size could be 
expressed by the Hall-Petch equation. The $0.2 \%$ proof strength and tensile strength of the annealed film are lower than those of the as-deposited film, while the fatigue limit of the annealed film was higher than that of the as-deposited film. The grain boundary stability and dislocation density are affected by annealing.

(4) The fracture strain of the annealed film is lower than that of the as-deposited film, and annealing makes the film brittle.

\section{Acknowledgement}

Supports of this work through by Grant-in-Aid for Challenging Exploratory Research (JSPS KAKENHI Grant Number 25630014) and Grant-in-Aid for Scientific Research (C) (JSPS KAKENHI Grant Number 18K03837) are gratefully acknowledged. The authors would like to thank Ms. K. Yokota, Mr. Y. Tsutsumi, and Mr. H. Enomoto (Graduate School, Kobe University) for their technical support.

\section{REFERENCES}

1) H. Gleiter: Acta Mater. 48 (2000) 1-29.

2) M.A. Meyers, A. Mishra and D.J. Benson: Prog. Mater. Sci. 51 (2006) 427-556.

3) M. Dao, L. Lu, R.J. Asaro, J.T.M. De Hosson and E. Ma: Acta Mater. 55 (2007) 4041-4065.

4) H.A. Padilla and B.L. Boyce: Exp. Mech. 50 (2010) 5-23.

5) K.S. Kumar, H.V. Swygenhoven and S. Suresh: Acta Mater. 51 (2003) 5743-5774.

6) A.M. El-Sherik and U. Erb: J. Mater. Sci. 30 (1995) 5743-5749.

7) S.D. Dahlgren, W.L. Nicholson, M.D. Mers, W. Bollmann, J.F. Devlin and R. Wang: Thin Solid Films 40 (1977) 345-353.

8) F. Ebrahimi, G.R. Bourne, M.S. Kelly and T.E. Matthewa: Nanostruct. Mater. 11 (1999) 343-350.

9) K. Tanaka, M. Sakakibara and H. Kimachi: Procedia Eng. 10 (2011) 542-547.

10) J. Hu, Y.N. Shij, X. Sauvage, G. Sha and K. Lu: Science 355 (2017) 1292-1296.

11) I. Matsui, N. Omura, T. Yamamoto and Y. Takigawa: Materia Japan 57 (2018) 479-486.

12) D. Jang and M. Atzmon: J. Appl. Phys. 99 (2006) 083504.

13) S. Ranganathan, R. Divaka and V.S. Raghunathan: Scr. Mater. 44 (2001) 1169-1174.

14) X.L. Wu and Y.T. Zhu: Appl. Phys. Lett. 89 (2006) 031922.

15) A. Hasnaoui, H.V. Swygenhoven and P.M. Derlet: Acta Mater. 50 (2002) 3927-3939.

16) O. Renk, A. Hohenwarter, K. Eder and K.S. Kormout: Scr. Mater. 95 (2015) 27-30.

17) R.Z. Valiev, E.V. Kozlov, Y.F. Ivanov, J. Lian, A.A. Nazarov and B. Baudelet: Acta Metall. Mater. 42 (1994) 2467-2475.

18) R.Z. Valiev: Nanostruct. Mater. 6 (1995) 73-82.

19) R.K. Islamgaliev, F. Chmelik and R. Kuzel: Mater. Sci. Eng. A 237 (1997) 43-51.

20) T. Hanlon, Y.N. Kwon and S. Suresh: Scr. Mater. 49 (2003) 675-680.

21) T. Hanlon, E.D. Tabachnikova and S. Suresh: Int. J. Fatigue 27 (2005) 1147-1158.

22) J. Xie, X. Wu and Y. Hong: Scr. Mater. 57 (2007) 5-8.

23) P. Cavaliere: Int. J. Fatigue 31 (2009) 1476-1489.

24) M.D. Sangid, G.J. Pataky, H. Sehitoglu and R.G. Rateick: Acta Mater 59 (2011) 7340-7355.

25) T. Kondo, X.C. Bi, H. Hirakata and K. Minoshima: Int. J. Fatigue 82 (2016) 12-28.

26) M. Goto, S.Z. Han, T. Yakushiji, S.S. Kim and C.Y. Lim: Int. J. Fatigue 30 (2008) 1333-1344.
27) P. Scherrer: Nachr. Ges. Wiss. Gottingen 26 (1918) 98-100.

28) M. Sone: Materia Japan 59 (2020) 490-494.

29) N.E. Dowling: Mechanical Behavior of Materials, Engineering Methods for Deformation, Fracture, and Fatigue, Third Edition, (Pearson Education, London, 1993) p. 418

30) S. Kikuchi, Y. Nukui, Y. Nakatsuka, Y. Nakai, M. Nakatani, M.O. Kawabata and K. Ameyama: Int. J. Fatigue 127 (2019) 222-228.

31) S. Taira, K. Tanaka and Y. Nakai: Mech. Res. Commun. 5 (1978) 375 381.

32) Y. Nakai and K. Tanaka: Proc. 23rd Jpn. Cong. Mater. Res., (1980) pp. 106-112.

33) K. Tanaka, Y. Nakai and M. Yamashita: Int. J. Fract. 17 (1981) 519533.

34) A.W. Thompson: Acta Metall. 25 (1977) 83-86.

35) K. Tanaka, Y. Koike, K. Sano, H. Tanaka, S. Machiya, T. Shobu and H. Kimachi: J. Soc. Mater. Sci. Jpn. 64 (2015) 528-535.

36) M.A. Miranda and R. Sasaki: Acta Crystallogr. Sec. A 74 (2018) 5465.

37) M.H. El Haddad, K.N. Smith and T.H. Topper: J. Eng. Mater. Technol. 101 (1979) 42-46.

38) H. Kitagawa and S. Takahashi: Trans. Jpn. Soc. Mech. Eng. 45 (1979) 1289-1303.

39) S. Usami and S. Shida: Fatigue Fract. Eng. Mater. Struct. 1 (1979) 471481.

40) K. Tanaka, Y. Murase and H. Kimachi: MATEC Web Conf. 165 (2018) 04011.

41) Y. Nakai, T. Hirai and S. Kikuchi: Eng. Fract. Mech., submitted.

42) I. Ohno: Kinzoku Hyomen Gijutsu 39 (1988) 149-155.

\section{Appendix Elastic elongation of dog bone shaped specimen}

Dimensions of the specimen are defined in Fig. A1. Area of cross section in Part B is given by

$$
A(\theta)=t\left(W_{1}+2(1-\cos \theta) R\right)
$$

where $t$ is the thickness of the specimen.

Elastic elongation of Part A, B, C are given by the following equations, respectively.

$$
\begin{aligned}
\delta_{\mathrm{A}}= & \frac{P l_{1}}{E W_{1} t} \\
\delta_{\mathrm{B}}= & 2 \int_{0}^{l_{2}} \frac{P}{E A(x)} \mathrm{d} x=\frac{4 P}{E} \int_{0}^{\phi} \frac{R \cos \theta}{A(\theta)} \mathrm{d} \theta \\
= & \frac{2 P}{E t}\left\{\frac{1+2 R / W_{1}}{\sqrt{1+4 R / W_{1}}} \tan ^{-1}\left(\frac{l_{2} \sqrt{1+4 R / W_{1}}}{2 R-W_{1}+W_{2}}\right)\right. \\
& \left.-\tan ^{-1}\left(\frac{l_{2}}{2 R-W_{1}+W_{2}}\right)\right\} \\
\delta_{\mathrm{C}}= & \frac{P l_{3}}{E W_{2} t}
\end{aligned}
$$

Total displacement of the specimen is

$$
\delta_{\mathrm{t}}=\delta_{\mathrm{A}}+2\left(\delta_{\mathrm{B}}+\delta_{\mathrm{C}}\right)
$$

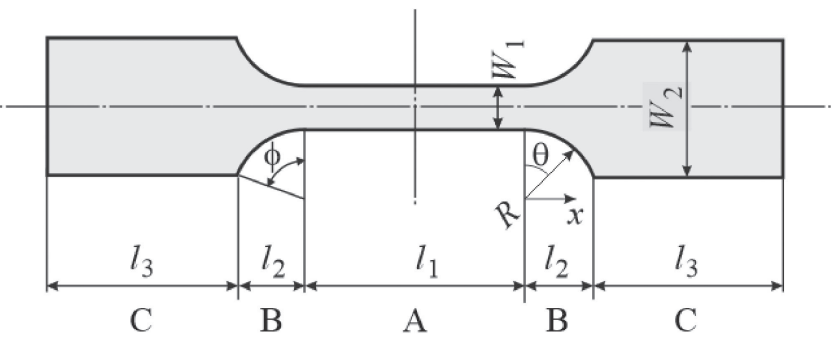

Fig. A1 Dimensions of dog bone shaped specimen. 